\title{
Investigation of Rheological Behavior of Self-Compacting and High Performance Composite Concretes
}

\author{
Rodrigo Andraus Bispo ${ }^{a *}$ (1), Gabriela Oliveira Vicente ${ }^{a}$, Gean Pereira da Silva Júnior ${ }^{a}$, \\ Daniel Ukuessunga Benjamim ${ }^{a}$, Marco Antonio de Morais Alcântara ${ }^{a}$ \\ ${ }^{a}$ Universidade Estadual Paulista Júlio de Mesquita Filho Campus de Ilha Solteira FEIS-UNESP, \\ Alameda Bahia, 550 - Zona Norte, Ilha Solteira, SP, Brasil.
}

Received: June 02, 2021; Revised: July 08, 2021; Accepted: July 21, 2021.

\begin{abstract}
This work describes proposed experimental methods for the characterization of concrete in fresh and hardened state, with the purpose of contributing to the experimental characterization of concrete. The main objective was to identify the rheological behavior of high performance (HP) and self-compacting (SC) concretes. Initially, a ordinary concrete composition was proposed, from which, silica fume $(5,10$ and $15 \%$ in mass) and superplasticizer ( $0.6 \%$ in mass) were added to obtain HPC and SCC. Furthermore, for the self-compacting concretes, a modification in granular skeleton was proposed, with a reduction of total aggregate percentage by $22.73 \%$ in relation to the other compositions. The interference of these modifications was evaluated on the behavior of fresh concrete though the flow and slump test and hardened concrete through mechanical properties. The results showed that the modification in the granular skeleton of ordinary concrete contributed directly to the reduction of inertia factors of SCC, favoring the mobility conditions. For both self-compacting and high performance concretes, consistency and mechanical strength gain over ordinary concrete were influenced when the silica fume and superplasticizer concentration was increased, limiting your properties gains to these additions.
\end{abstract}

Keywords: Concrete, Rheology, Silica Fume, Superplasticizer.

\section{Introduction}

Concrete's versatility, ease of execution, freedom in modeling, low cost and mechanical strength makes it one of the most used building materials in the world. The search for increasingly challenging and complex structures that meet high performance parameters, contributes to the growth of studies of different classes of concrete, including Self-Compacting Concrete (SCC) and High Performance Concrete (HPC).

HPC presents high strength, durability and workability ${ }^{1}$. Other HPC properties are high density, high modulus of elasticity, resistance to aggressive environmental attacks and low permeability ${ }^{2}$. This composite concrete has been used for different purposes nowadays ${ }^{3-5}$. SCC has as main characteristics the absence of the need for compacting and the fluidity required. Fluidity, resistance to segregation and exudation, are relevant properties in the study of $\mathrm{SCC}^{6}$.

A several researches have been conducted in recent years; however, there were few scientific productions that correlated these topics. Figure 1 show the number of annual publications.

Superplasticizers are also known as water reducers due their ability to fluidify the concrete mix without the need to add more water to the system. Up to $1 \%$ by weight of cement

*e-mail: rodrigoandrausbispo@gmail.com may be incorporated into mixtures without causing a lot off exudation and retardation of the setting ${ }^{1}$.

Fresh concretes with slump values above $220 \mathrm{~mm}$ and slump flow values above $600 \mathrm{~mm}$ may be considered as self-compacting. This property can be achieved with a higher concentration of cement paste in relation to aggregates ${ }^{1}$.

Were evaluated the slump flow of self-compacting concretes with filler additions from different sources, like a Limestone (L) $\left(2.8 \mathrm{~g} / \mathrm{cm}^{3}\right)$, Diabase (D) $\left(2.82 \mathrm{~g} / \mathrm{cm}^{3}\right)$ and Gneiss $(\mathrm{G})\left(2.77 \mathrm{~g} / \mathrm{cm}^{3}\right)$. For the concrete that served as a reference, without any additions, the flowing was $650 \mathrm{~mm}$. With the additions, the flowing varied as follows: L: 667 until $710 \mathrm{~mm}$; D: 559 until $692 \mathrm{~mm}$ and G: 651 until $689 \mathrm{~mm}$ according to the replacement percentage ${ }^{7}$.

The main objective of this research was to identify the rheological behavior of HPC and SCC. For this, concrete traces containing different filler and superplasticizer proportions were produced with variation in the granular skeleton. The consistency and cohesion of fresh concrete were evaluated by the flow and slump test. Compressive strength and tensile strength of hardened concrete were determined at 28 days. The water/cement ratio, paste/cement ratio, water/(cement+filler) ratio, Silica Fume/cement ratio, superplasticizer/cement ratio, total aggregate/cement ratio, mortar/coarse aggregate ratio, paste/fine aggregate ratio were also evaluated. 


\section{Materials and Methods}

\subsection{Raw materials}

The binder used in this research was CP II-Z Portland Cement Composite with Pozolana. The sand of Nossa Senhora Aparecida Port (Brazil) with a true density of $2.65 \mathrm{~g} / \mathrm{cm}^{3}$ and a bulk density of $1.48 \mathrm{~g} / \mathrm{cm}^{3}$ was used as fine aggregate. Its fineness module is 1.67 and the maximum particle diameter $1.19 \mathrm{~mm}$.

Basalt from the Três Irmãos Quarry (Brazil) was used as a coarse aggregate. The particle range between 4.8 and $9.5 \mathrm{~mm}$ was used for the coarse aggregate. A reduction in the amount of coarse particles in the SCC has been established aiming at better packing and consequent increase in flowability. The true density, fineness module and maximum particle diameter was $2.61 \mathrm{~g} / \mathrm{cm}^{3}, 3.85$ and $9.62 \mathrm{~mm}$ respectively. Figure 2 shows the particle size distribution of aggregates.

Third generation Sika ViscoCrete ${ }^{\circledR} 20 \mathrm{HE}$ superplasticizer was used, at a ratio of $0.6 \%$ to cement mass. It's an aqueous solution of modified polycarboxylates with density of $1 \mathrm{~g} / \mathrm{cm}^{3}$ and $\mathrm{pH} 5 \pm 1$. Was employed Silica Fume (SF), with specific surface of $20 \mathrm{~m}^{2} / \mathrm{g}$, in the proportion of 5,10 and $15 \%$ in relation to cement mass.

\subsection{Mixture proportion and specimen preparation}

For this research three types of concrete were made, namely: Ordinary Concrete $(\mathrm{OC})^{8}$, which was adapted through modifications in its constituents giving rise to the Self-compacting Concrete (SCC) and the High Performance Concrete (HPC). For each concrete three traces with different Silica Fume (SF) and superplasticizer proportions were proposed according to Table 1. A mass reduction of aggregates for the SCC of $22.73 \%$ has been proposed according the Figure 3.

The reduction of coarse and fine aggregate in SCC traces contributed to the reduction of inertia factors, resulting in greater flowability as the amount of concrete paste and mortar increases in relation to aggregates. This can be observed in increasing mortar/coarse aggregate ratio and paste/fine aggregate ratio and decreasing in the total aggregate/cement ratio expressed in Table 2 .

Six cylindrical specimens with $100 \mathrm{~mm}$ in diameter and $200 \mathrm{~mm}$ high were molded for each mix proportion, totaling 54 specimens. For the OC and the HPC a vibratory table was

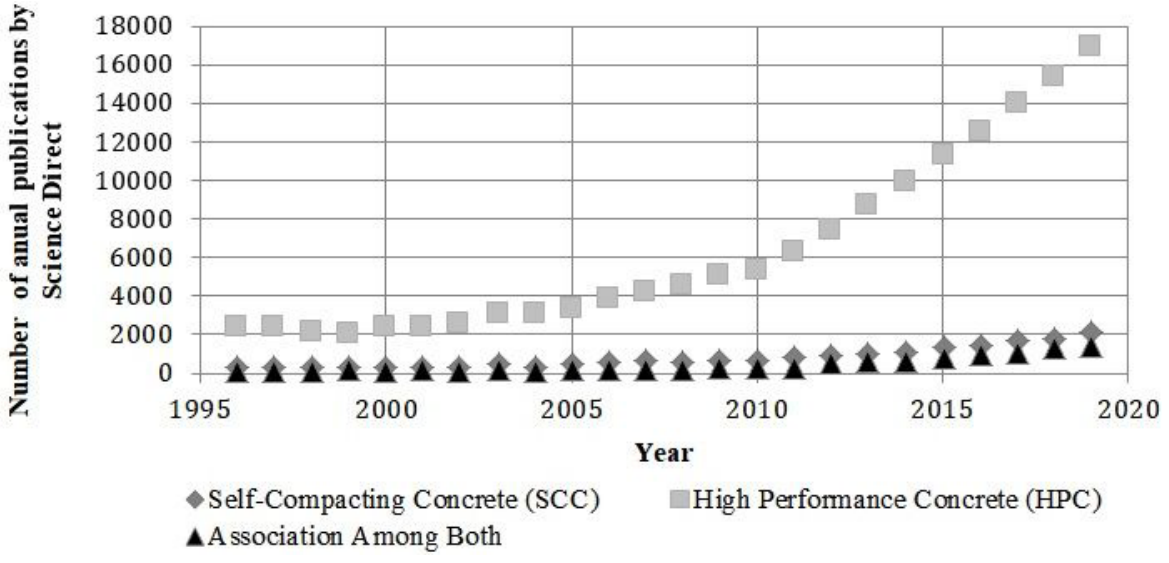

Figure 1. Number of annual publications about SCC, HPC and both in relation to the year by Science Direct.

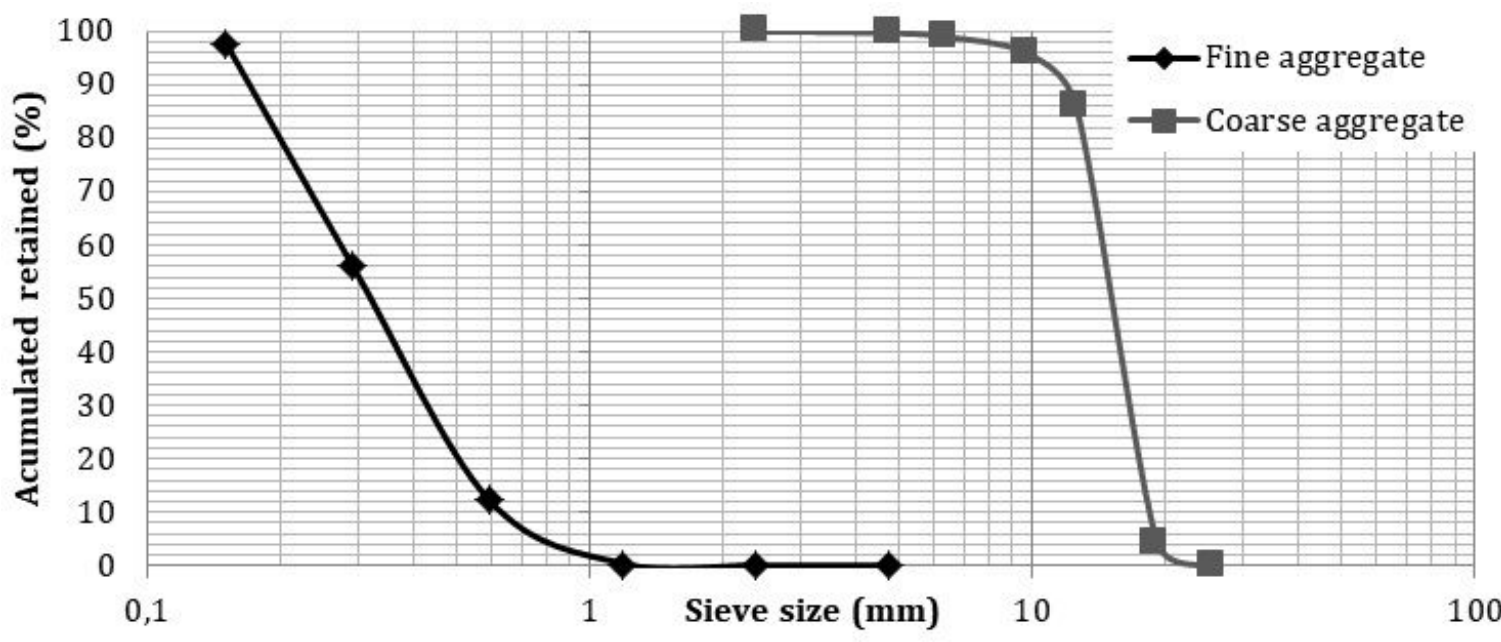

Figure 2. Particle size distribution of aggregates. 
Table 1. Proportions of materials of concrete traces.

\begin{tabular}{|c|c|c|c|c|c|c|c|c|c|}
\hline \multirow{2}{*}{ Materials } & \multicolumn{3}{|c|}{ Ordinary Concrete } & \multicolumn{3}{|c|}{ Self-Compacting Concrete } & \multicolumn{3}{|c|}{ High Performance Concrete } \\
\hline & T1 & T2 & T3 & T1 & T2 & T3 & T1 & T2 & T3 \\
\hline Cement & 5.0 & 5.0 & 5.0 & 5.0 & 5.0 & 5.0 & 5.0 & 5.0 & 5.0 \\
\hline Silica Fume & 0 & 0 & 0 & 0.25 & 0.5 & 0.75 & 0.25 & 0.5 & 0.75 \\
\hline Fine aggregate & 11.0 & 11.0 & 11.0 & 8.5 & 8.5 & 8.5 & 11.0 & 11.0 & 11.0 \\
\hline Coarse aggregate & 11.0 & 11.0 & 11.0 & 8.5 & 8.5 & 8.5 & 11.0 & 11.0 & 11.0 \\
\hline Total dry materials & 27.0 & 27.0 & 27.0 & 22.25 & 22.5 & 22.75 & 27.25 & 27.5 & 27.75 \\
\hline water & 2.45 & 2.48 & 2.5 & 2.45 & 2.48 & 2.5 & 2.45 & 2.48 & 2.5 \\
\hline Superplasticizer & 0 & 0 & 0 & 0.03 & 0.03 & 0.03 & 0.03 & 0.03 & 0.03 \\
\hline
\end{tabular}

Table 2. Ratio of materials of concrete traces.

\begin{tabular}{|c|c|c|c|c|c|c|c|c|c|}
\hline \multirow{2}{*}{ Ratio } & \multicolumn{3}{|c|}{ Ordinary Concrete } & \multicolumn{3}{|c|}{ Self-Compacting Concrete } & \multicolumn{3}{|c|}{ High Performance Concrete } \\
\hline & T1 & T2 & T3 & T1 & T2 & T3 & T1 & T2 & T3 \\
\hline Water/cement & 0.49 & 0.496 & 0.5 & 0.49 & 0.496 & 0.5 & 0.49 & 0.496 & 0.5 \\
\hline Paste/cement & 1.49 & 1.496 & 1.5 & 1.54 & 1.596 & 1.65 & 1.54 & 1.596 & 1.65 \\
\hline Water/(cement + sílica fume) & 0.49 & 0.496 & 0.5 & 0.467 & 0.451 & 0.435 & 0.467 & 0.451 & 0.435 \\
\hline Silica fume/cement & 0 & 0 & 0 & 0.05 & 0.1 & 0.15 & 0.05 & 0.1 & 0.15 \\
\hline Superplasticizer/cement & 0 & 0 & 0 & 0.006 & 0.006 & 0.006 & 0.006 & 0.006 & 0.006 \\
\hline Total aggregate/cement & 4.4 & 4.4 & 4.4 & 3.4 & 3.4 & 3.4 & 4.4 & 4.4 & 4.4 \\
\hline Mortar/coarse aggregate & 1.677 & 1.68 & 1.682 & 1.906 & 1.939 & 1.971 & 1.7 & 1.725 & 1.75 \\
\hline Paste/fine aggregate & 0.677 & 0.68 & 0.682 & 0.906 & 0.939 & 0.971 & 0.7 & 0.725 & 0.75 \\
\hline Total dry materials/water & 0.091 & 0.092 & 0.093 & 0.110 & 0.110 & 0.110 & 0.090 & 0.090 & 0.090 \\
\hline
\end{tabular}

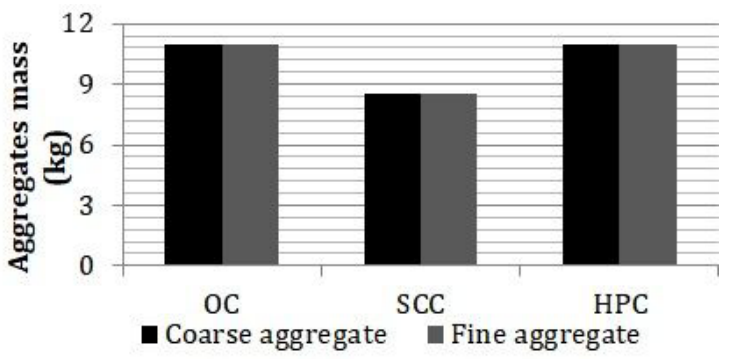

Figure 3. Reduction of aggregate in mass.
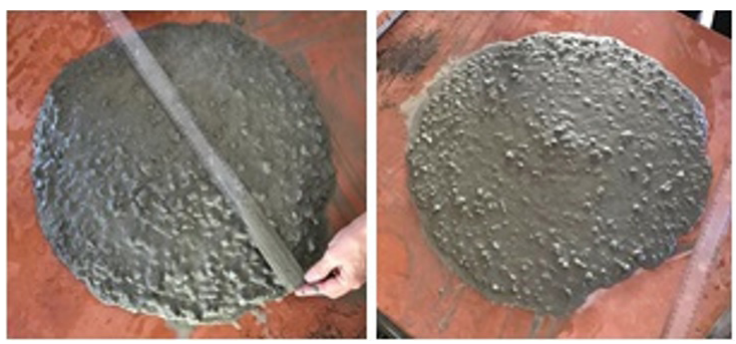

Figure 4. Slump flow measurement (a) HPC (b) SCC.

utilized to compact the concrete and eliminates voids. For the SCC this step was not employed due to its rheological characteristic. After 24 hours the specimens were demolded and stored at room temperature $\left(\mathrm{t}=25^{\circ} \mathrm{C}, \mathrm{HR}=95 \%\right)$ until the age of 28 days.

\subsection{Experimental methods of fresh and hardened concrete}

Fresh concrete was evaluated according the flow and slump tests. For hardened concrete, experimental methods were proposed to evaluate mechanical properties (tensile

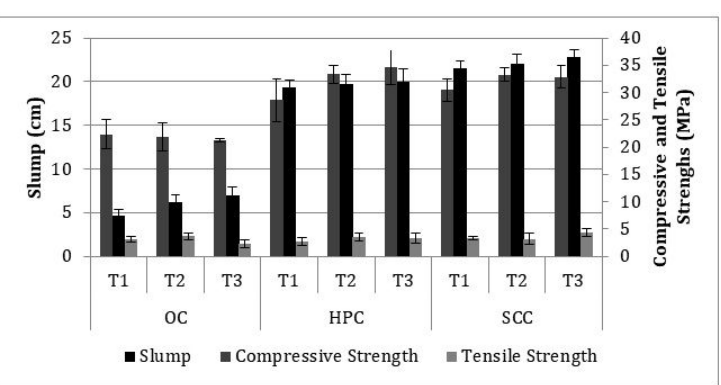

Figure 5. Comparative among slump and hardened concrete strengths.

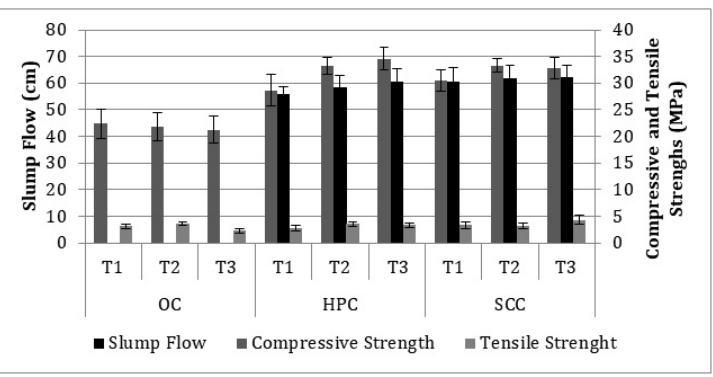

Figure 6. Comparative among slump flow and hardened concrete strengths.

and compressive strengths). Figure 4 below show the slump flow test for HPC and SCC.

\section{Results and Discussion}

The results of slump and slump flow are present in Figures 5 and 6 below. Compression, tensile strength values of OC, HPC and SCC were also expressed. The correlation among the highest slump and a decrease in compressive and 
tensile strengths is seen in the OC in Figure 5. The traces with the highest water/cement ratio had the greatest slump and slump flow, thus, the decrease in mechanical strength values.

However, for HPC and SCC the trend was opposite, resulting in a gain in mechanical strength associated with the greater slump, even when the water/cement ratio was increased. This happened due to the admixtures of superplasficizer and the gradual increasing of SF. Tensile strength of SCC specimens may have increased due to decreased aggregate/ paste interface amount, reaching resistence levels of the order of HPC, even with a smaller amount of coarse aggregate, this highlights the importance of paste quality and good confinement of the aggregate by the cement matrix.

According to studies ${ }^{9}$, SCC with granular skeletal modifications and variation in Mortar Film Thickness (MFT) had tensile strength gain. Figure 7 shows the correlation among the six mechanical strength (compression and tensile) values of each concrete type (OC, HPC and SCC) and their slump values. For OC there was a linear decreasing trend of the proposed correlation, pointing to a decrease in resistance
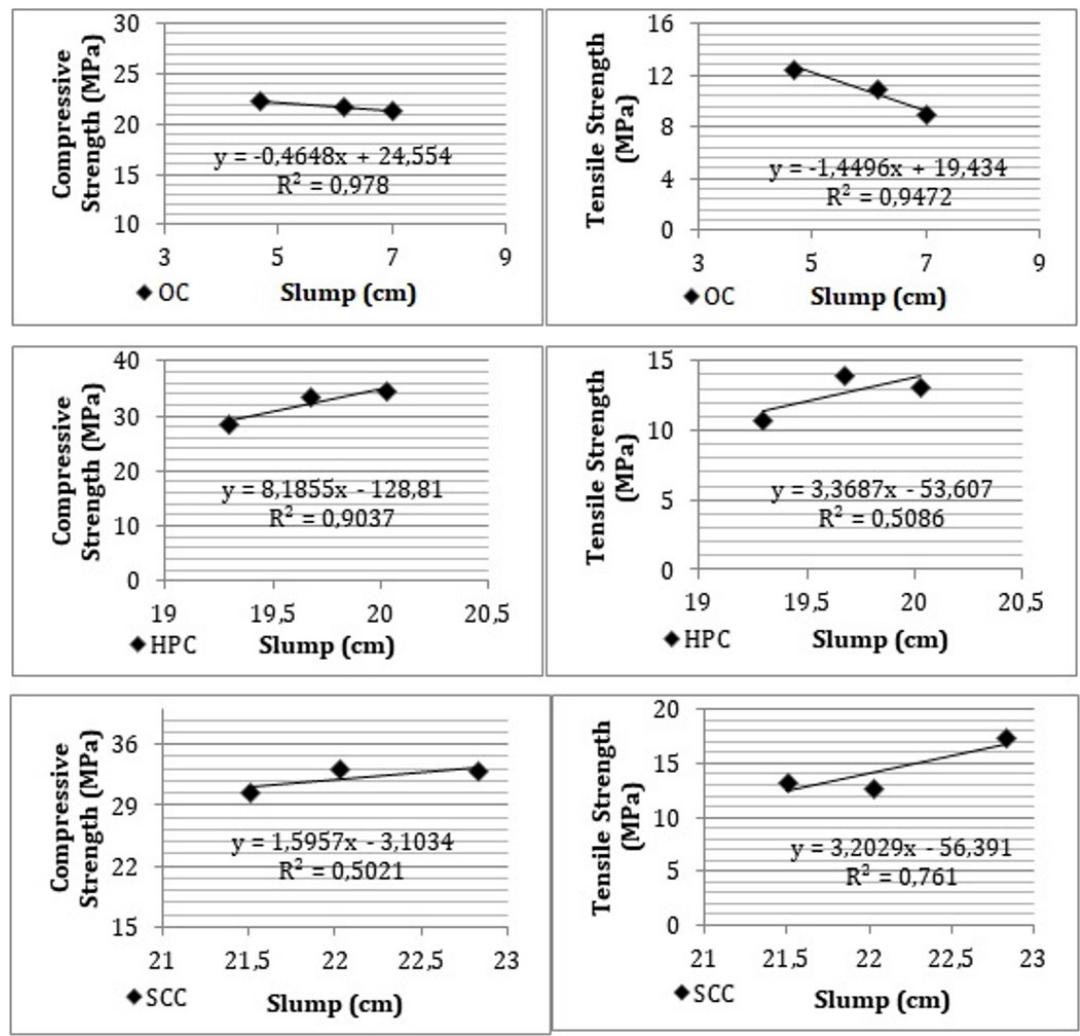

Figure 7. Correlation among slump and mechanical strength in OC, HPC and SCC.
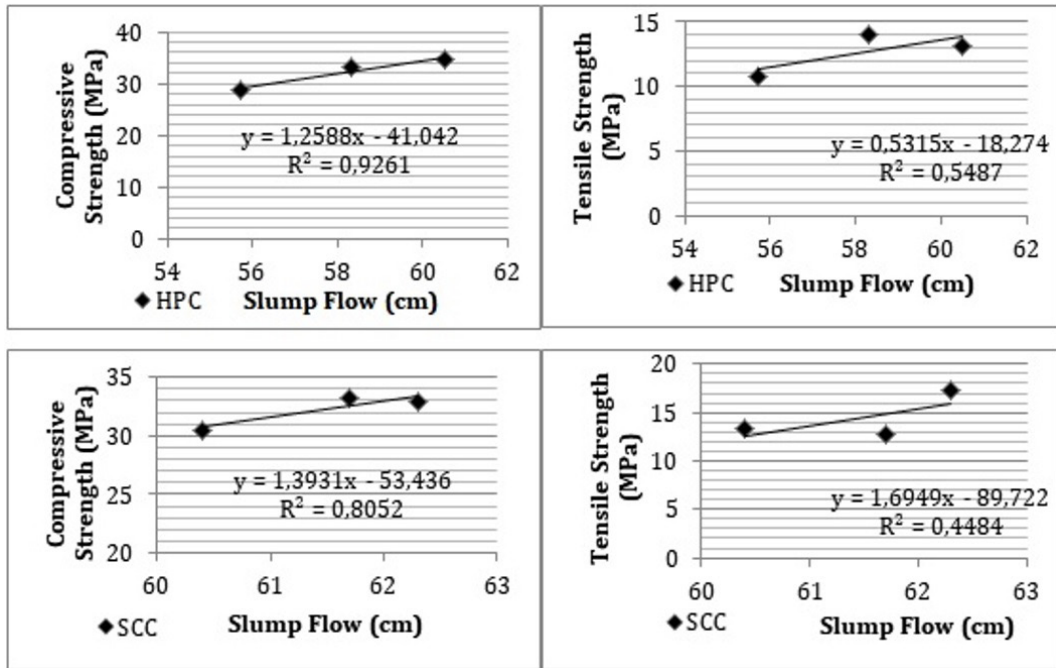

Figure 8. Correlation among slump flow and mechanical strength in HPC and SCC. 
with increasing slump. For the HPC and SCC there is a linear increasing trend, proving the resistance gain with increasing slump. The same trend of mechanical strength gain occurs in HPC and SCC when slump flow increases (Figure 8).

\section{Conclusion}

1. The modification in the granular skeleton of ordinary concrete contributed directly to the reduction of inertia factors favoring the mobility conditions, allowing the production of SSC.

2. For SC and HP concretes the consistency increased as the addition of silica fume compared to ordinary concrete due to increased paste formation and consequence decreased internal friction.

3. The compressive strength and tensile strength of the SC and HP concretes presented gain with the increase in the results of slump and slump flow tests, opposite behavior to that of ordinary concrete. This is possibly due to the addition of silica fume and superplasticizer to the mixtures.

\section{Acknowledgements}

The authors gratefully acknowledge the financial support provide by CAPES - Coordenação de Apereiçoamento de Pessoal de Nível Superior and INAGBE - Instituto Nacional de Gestão de Bolsas de Estudos da Angola.

\section{References}

1. Mehta PK, Monteiro PJM. Concreto microestrutura, propriedades e materiais. São Paulo: IBRACON; 2008.

2. Neville A, Aitcin PC. High performance concrete: an overview. Mater Struct. 1998;31(2):111-7..

3. Yong S, Zonglin W, Qingfei G, Chenguang L. A new mixture design methodology based on the Packing Density Theory for high performance concrete in bridge engineering. Constr Build Mater. 2018;182:80-93.

4. Zhu P, Brunner S, Zhao S, Griffa M, Leemann A, Toropovs N, et al. Study of physical properties and microstructure of aerogel-cement mortarsfor improving thefire safety of highperformance concrete linings in tunnels. Cement Concr Compos. 2019;104:103414.

5. Yang L, Yao Z, Xue W, Wang X, Kong W, Wu T. Preparation, performance test and microanalysis of hybrid fibers andmicroexpansive high-performance shaft lining concrete. Constr Build Mater. 2019;223:431-40.

6. Skarendahl A, Petersson O. $1^{\text {st }}$ International RILEM Symposium on Self-Compacting Concrete: Materials and Structures. Paris: RILEM; 2000. p. 143-4.

7. Schankoski RA, Pilar R, Matos PR, Prudêncio LR Jr, Ferron $\mathrm{RD}$. Fresh and hardened properties of self-compacting concretes produced with diabase and gneiss quarry by-product powders as alternative fillers. Constr Build Mater. 2019;224:659-79.

8. Petrucci EGR. Concreto de Cimento Portland. Porto Alegre: Globo; 1981

9. Li J, Chen Y, Wan C. A mix-design method for lightweight aggregate self-compacting concrete based on packing and mortar film thickness theories. Constr Build Mater. 2017;157:621-34. 